\title{
Non-injected illicit drugs and alcohol and HIV- related high-risk sexual behaviors in a street- recruited sample of non-injecting drug users in New York City
}

Ashutosh Mishra*, Daniel Pilowsky, Judith Jacobson

From $16^{\text {th }}$ International Symposium on HIV and Emerging Infectious Diseases

Marseille, France. 24-26 March 2010

\section{Background}

Unlike injecting drug use, non-injecting drug use has not been definitively shown to be a risk factor for the sexual transmission of Human Immunodeficiency Virus (HIV) infections. HIV-related high-risk sexual behaviors would be more prevalent among non-injecting cocaine users than non-users and among multidrug users than single drug users.

\section{Methods}

Among the Non-Injecting Drug Users (NIDUs) in the South Bronx and Harlem, New York City questionnaires were administered about the past use and within last three months use of crack cocaine and powder cocaine, alcohol, marijuana/hashish, and heroin and HIV-related sexual behaviors. Sexual behavior was summarized as a single variable, the Vaginal Equivalent Episode (VEE) score; VEE scores above and below the median were categorized as high and low sexual risk respectively.

\section{Results}

Among 264 NIDUs who completed the questionnaires, 132(84 males, 48 females) used crack cocaine, 139 (101 males, 38 females) powder cocaine, 194 (140 males, 54 females) marijuana/hashish, and 110 (71 males, 39 females) heroin in the last three months. In a model that controlled for age and sex, only powder cocaine was associated with HIV-related sexual behaviors (recent use $\mathrm{AOR}=1.87$; 95\% CI: 1.19-2.93; past use $\mathrm{AOR}=2.50$; $95 \%$ CI: 1.08-5.81). High-risk sexual behaviors were also

* Correspondence: mishraashutosh@yahoo.com Columbia University, New York, USA more common among the users of all four drugs studied than among users of only one (OR $=1.50$; $95 \% \mathrm{CI}$ : 1.05 2.13).

\section{Discussion}

Like some earlier studies, the present study found cocaine to be strongly correlated with high-risk sexual behaviors. Future research is needed on the mechanisms of that association and on the association of the use of other non-injecting illicit drugs with HIV-related sexual behaviors. The results also support the promotion of HIV preventive measures, such as condoms, among sexually active NIDUs.

Published: 11 May 2010

\section{doi:10.1186/1742-4690-7-S1-P106}

Cite this article as: Mishra et al: Non-injected illicit drugs and alcohol and HIV-related high-risk sexual behaviors in a street-recruited sample of non-injecting drug users in New York City. Retrovirology 2010 7(Supp 1):P106.

Submit your next manuscript to BioMed Central and take full advantage of:

- Convenient online submission

- Thorough peer review

- No space constraints or color figure charges

- Immediate publication on acceptance

- Inclusion in PubMed, CAS, Scopus and Google Scholar

- Research which is freely available for redistribution 